\title{
Os processos fonológicos da síncope em palavras proparoxítonas
}

\author{
Giselly de Oliveira Lima
}

Mestra em Linguística pela Universidade Federal

de Uberlândia. Assessora Pedagógica da

Secretaria Municipal de Educação de Rio Verde-

MG.

Resumo: Este artigo apresenta os processos fonológicos que estão diretamente envolvidos com a síncope nas proparoxítonas no Sudoeste Goiano. Entre esses processos, focaliza-se a ressilabação, assimilação e a reestruturação dos pés métricos. Com as avaliações feitas aqui, espera-se evidenciar que os processos fonológicos, provocados pela síncope da vogal postônica, podem ser explicados pelos modelos métricos de Selkirk (1982), para a sílaba, e de Hayes (1995) para o acento.

Palavras-chave: Síncope; Proparoxítonas; Modelos métricos
Abstract: This article introduces the phonological processes which are directly involved in proparoxytone syncope in the speech variation of the Southwest of Goiás (Brazil). Among these processes the main focus is on resyllabification, assimilation and restructuring of metric feet. Based on such evaluations, it is intended to highlight that phonological processes, triggered by posttonic vowel syncope, can be explained by Selkirk's metric model (1982), for the syllable, and Hayes' (1995) for the accent.

Keywords: Syncope; Proparoxytone; Metric models 



\section{A síncope}

O dinamismo da língua, marcado por fenômenos fonológicos, sempre esteve presente nos estudos linguísticos. Callou e Leite (2003, p. 43-44) consideram que a língua, por ser dinâmica por natureza, está suscetível a sofrer modificações determinadas por fatores fonéticos, morfológicos e sintáticos. As autoras pontuam, ainda, que "as modificações sofridas pelos segmentos no eixo sintagmático podem alterar ou acrescentar traços, eliminar ou inserir segmentos". Tais alterações podem ocorrer no nível fonológico da língua, bem como podem alterar o nível fonético. Assim sendo, a síncope é um fenômeno fonológico que modifica palavras proparoxítonas por meio do apagamento da vogal postônica.

Os processos de mudança, em palavras proparoxítonas, podem ser observados no momento sincrônico, bem como é possível encontrar exemplos no processo evolutivo da língua. Isso significa que, diacronicamente, os processos históricos que fizeram parte da evolução do Latim para o Português continuam atuantes. A síncope é um bom exemplo, por se tratar de uma regra que teve sua origem no Latim vulgar e que continua atuando nas proparoxítonas, no caso desta pesquisa, no Sudoeste Goiano.

A síncope configura um processo fonológico que pode ser explicado a partir da estrutura da sílaba. Isso significa que o apagamento da vogal no interior de uma palavra faz com que a sílaba seja reestruturada, adequando-se à fonotática da língua. De acordo com Amaral (2002, p. 102), “a síncope em proparoxítonas é previsível, ou seja, o falante tem consciência das regras fonotáticas da língua ao reduzir sílabas, apagar segmentos ou inserir outros". Isso se deve ao fato de que o falante reconhece que o apagamento de uma vogal só é possível quando a sequência de fonemas estiver de acordo com o padrão silábico da língua. 
Confirmando, portanto, os argumentos de Amaral, os informantes desta pesquisa demonstraram consciência de que o apagamento só era possível se a reestruturação da sílaba estivesse de acordo com o padrão silábico do $\mathrm{PB}$, por exemplo.

(1)

$\begin{array}{llll}\text { último } & \text { ul. } \mathrm{t}[\varnothing] . \mathrm{mo} & \text { ult. } \mathrm{mo}^{*} & \text { ul. tmo* } \\ \text { lógico } & \text { ló.g[ø]. co } & \text { log. } \mathrm{co}^{*} & \text { lo. gco* } \\ \text { chácara } & \text { chá. } \mathrm{c}[\varnothing] . r a & \text { chác. } \mathrm{ra}^{*} & \text { chá.cra } \\ \text { fósforo } & \text { fós.f[ø].ro } & \text { fósf. ro* } & \text { fós. fro }\end{array}$

Como se pode notar nos exemplos em (1), as palavras "chácara" e "fósforo", com a síncope da vogal postônica, mudam a posição do acento da antepenúltima para penúltima sílaba. Desse modo, a síncope não só favorece a reestruturação da sílaba, como também altera a posição do acento. Tomemos os exemplos em (2).

(2) Síncope nas proparoxítonas

A.
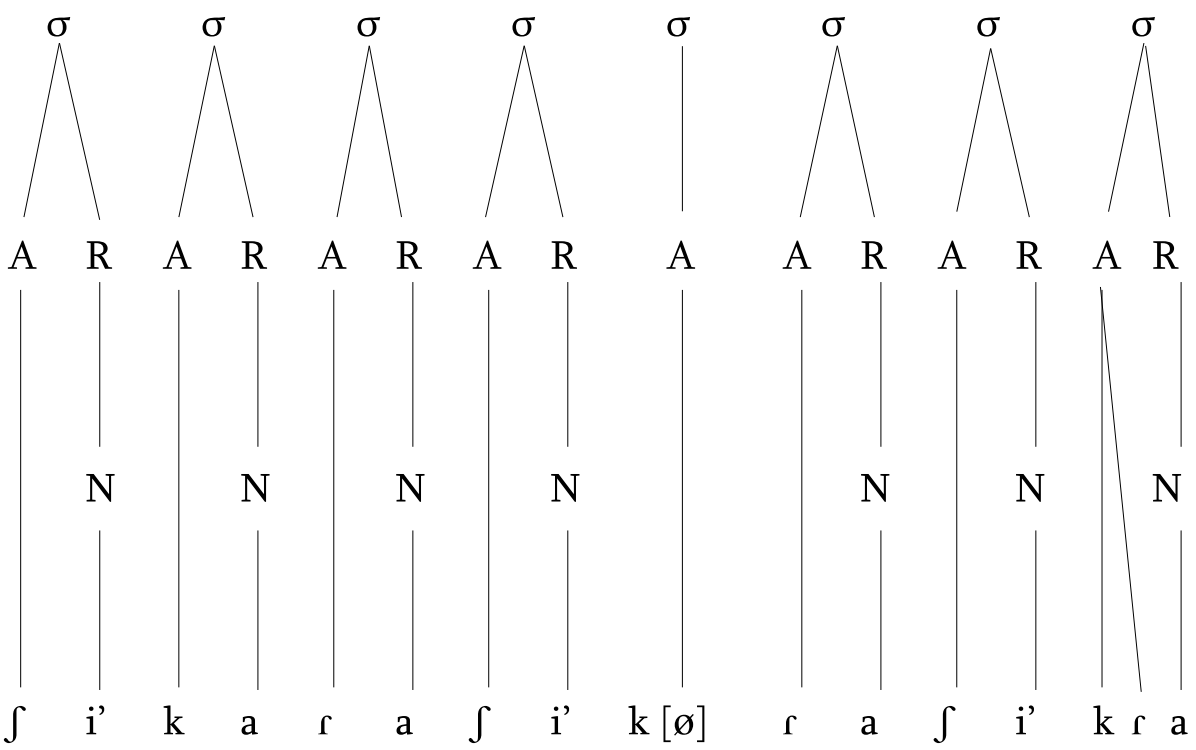
B.

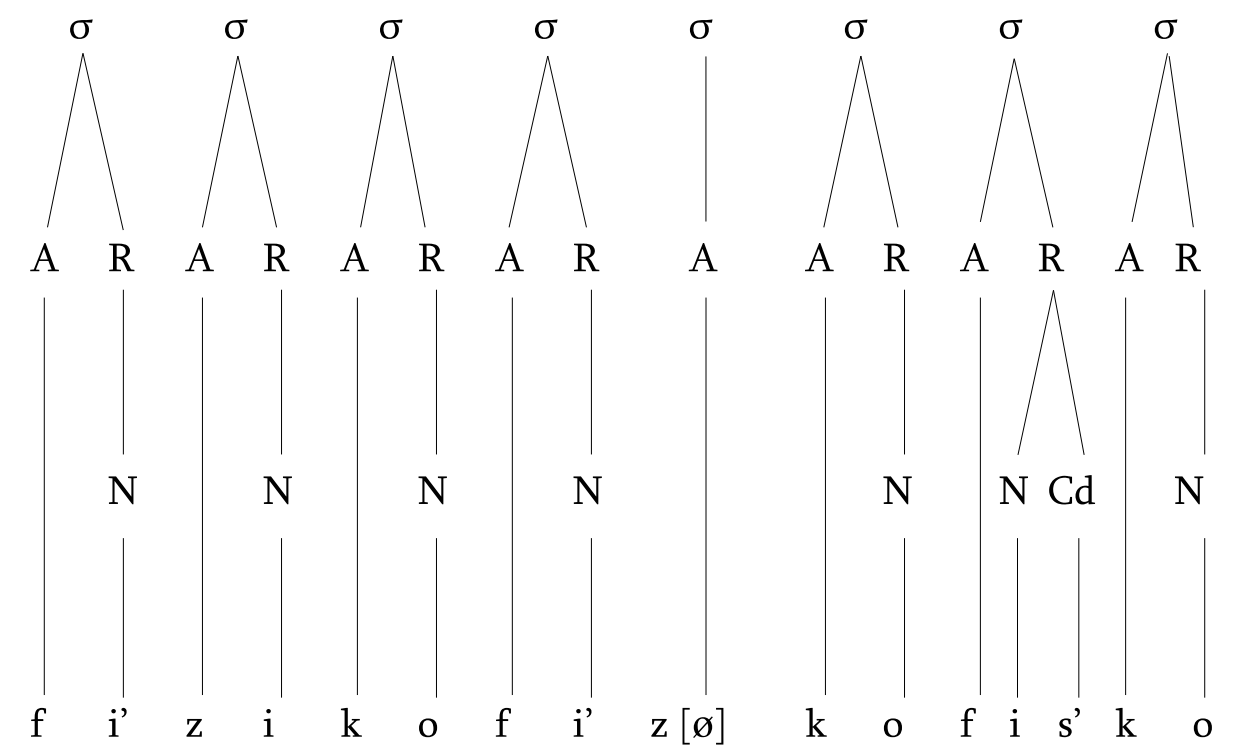

Pelos exemplos dados em (2a) e (2b) podemos considerar que o apagamento da vogal postônica cria uma nova estrutura silábica. No primeiro caso (2a), a consoante flutuante $/ \mathrm{k} /$ une-se à consoante da última sílaba, formando um ataque complexo [kr]; já no segundo caso (2b), a consoante / $\mathrm{z} /$ é incorporada à vogal da primeira sílaba, ocupando a posição de coda. Nos dois casos, a incorporação do segmento flutuante respeita a fonotática da língua, e, também, transforma palavras com acento antepenúltimo em paroxítonas.

Nossos dados revelaram que as vogais postônicas em palavras proparoxítonas, quando não sofrem os efeitos da síncope, podem, em certos contextos, apresentar alternância entre vogal média e vogal alta. Isso ocorre quando a fonotática da língua não permite o apagamento da vogal postônica ou, então, quando outro processo fonológico, como a neutralização, acontece em lugar da síncope. A esse respeito, Battisti e Vieira (2005) esclarecem que

No português do Brasil, existe um grande número de regras fonológicas que atuam sobre o sistema vocálico, tanto por razões prosódicas, fonotáticas quanto por razões morfológicas. Na maior parte 
das vezes, o alvo dessas regras fonológicas são as vogais médias que ora alternam entre si, ora alternam com as vogais altas. (BATTISTI e VIEIRA, 2005, p. 171)

Conforme Câmara Jr. (1976), na posição medial, o sistema vocálico é composto por quatro segmentos. $\mathrm{O}$ autor considera que a neutralização para posição postônica acontece somente entre o /o/ e o /u/, sendo a grafia com o ou com u mera convenção da escrita. A neutralização entre /e/ e /i/ não é referida pelo autor. No entanto, nossos dados, em (3), têm comprovado que a neutralização ocorre também entre /e/ e /i/, embora se tenha mostrado menos frequente do que $/ \mathrm{o} / \mathrm{e} / \mathrm{u} /$.

$\begin{array}{ll}\text { Neutralização entre } / \mathrm{e} / \mathrm{e} / \mathrm{i} / & \text { Neutralização entre } / \mathrm{o} / \mathrm{e} / \mathrm{u} / \\ \text { quilôm }[\mathrm{e}] \text { tro }>\text { quilôm }[\mathrm{i}] \text { tro } & \text { per }[\mathrm{o}] \mathrm{la}>\text { per }[\mathrm{u}] \mathrm{la} \\ \text { córr }[\mathrm{e}] \text { go }>\text { córr }[\mathrm{i}] \text { go } & \text { ép }[\mathrm{o}] \mathrm{ca}>\text { ép }[\mathrm{u}] \mathrm{ca} \\ \text { pêss }[\mathrm{e}] \text { go }>\text { pêss }[\mathrm{i}] \text { go } & \text { côm }[\mathrm{o}] \text { do }>\text { cômudo } \\ \text { cóc }[\mathrm{e}] \text { gas }>\text { cóc }[\mathrm{i}] \text { gas } & \text { fósf }[\mathrm{o}] \mathrm{ro}>\text { fósf }[\mathrm{u}] \mathrm{ro} \\ \text { cér }[\mathrm{e}] \text { bro }>\text { cér }[\mathrm{i}] \text { bro } & \text { abób }[\mathrm{o}] \mathrm{ra}>\mathrm{abób}[\mathrm{u}] \mathrm{ra}\end{array}$

Segundo Bisol (2003), o processo de neutralização no $\mathrm{PB}$, proposto por Câmara Jr., cria uma assimetria no subsistema de vogais postônicas mediais contrariando, assim, a tendência à simetria, que todas as línguas naturais possuem. Para tanto, a autora sustenta a hipótese de que as vogais postônicas mediais "flutuam" entre o subsistema das átonas finais e das pretônicas, ficando, então, a grade de vogais flutuando entre três e cinco segmentos. Para justificar a flutuação da postônica medial em direção ao subsistema das vogais pretônicas, a referida autora aponta dois argumentos, a saber:

1. Há, nos dialetos da região Sul, manifestações de alternâncias vocálicas como as seguintes: fósforo fósfuro, abóbora abóbura e alfândega alfândiga, epêntese epêntise, córrego córrigo, 
prótese prótise. Alternâncias estas que, por si, levam por terra a hipótese de Câmara Jr., pois indicam a presença do fonema /o/ em posição postônica não final.

2. É possível relacionar, assim como no subsistema de vogais pretônicas, vogais neutralizadas a vogais preservadas (por derivação), como nos exemplos: perolar < pérula pérola; fosforear < fósfuro fósforo; alfandegário < alfândiga alfândega. (BISOL, 2003, p. 280).

Por fim, cabe salientar que como o objetivo geral deste artigo é verificar os efeitos da síncope em palavras proparoxítonas, uma discussão mais aprofundada sobre a neutralização das vogais postônicas não será tratada aqui. Desse modo, abordaremos apenas os processos fonológicos desencadeados pela síncope, tais como a ressilabação, assimilação e reestruturação dos pés métricos. $\mathrm{Na}$ sequência, faremos uma discussão sobre cada um desses processos, bem como a atuação de cada um no corpus desta pesquisa.

\subsection{A ressilabação}

O processo de ressilabação, segundo Bisol (1996, p. 161), “[...] consiste em agregar consoantes em torno de picos de sonoridades que projetam sílabas. Esses picos são, em português, necessariamente vogais (V).” O Princípio de Sonoridade Sequencial (PSS) determina que o grau de sonoridade dos segmentos, que margeiam o núcleo silábico e/ou pico, deve ser crescente do ataque para o núcleo e decrescente do núcleo para a coda. De acordo com a Escala de Sonoridade (BONET e MASCARÓ, 1997), as oclusivas constituem os segmentos menos sonoros. Já as vogais apresentam a sonoridade máxima.

Além do PSS, o Princípio do Licenciamento Prosódico estabelece que todas as unidades fonológicas devem pertencer a unidades prosódicas superiores, isto 
é, segmentos devem pertencer a sílabas, as sílabas devem pertencer aos pés, os pés à palavra fonológica ${ }^{1}$. Assim, com o apagamento da vogal postônica, o segmento, que antes ocupava a posição de ataque, deverá ser incorporado a uma sílaba, sendo ela a tônica, ou então à sílaba átona final. Contudo, para que esse segmento seja incorporado a uma sílaba, esse deverá obedecer ao Princípio de Sonoridade Sequencial.

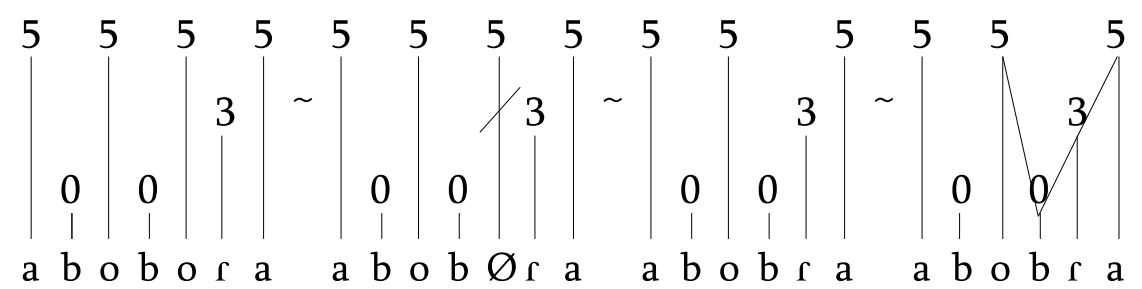

${ }^{1}$ Apenas estas três unidades prosódicas são relevantes para nossa pesquisa, uma vez que nos propusemos a analisar somente palavras proparoxítonas.
Considerando o PSS, a palavra abóbora, após sofrer o apagamento da vogal postônica, poderia ser silabada como a.bob.ra ou como a.bo.bra. Para resolver esse problema, deve-se considerar a condição de língua particular e o Princípio de Maximização do Ataque (PMA). Desse modo, a condição de língua particular do $\mathrm{PB}$, que proíbe oclusivas em posição de coda, exclui a forma assilabada a.bob.ra. Já o Princípio de Maximização do Ataque (PMA) determina que o ataque seja maximizado em conformidade com o PSS. Isso significa que, pela silabação, primeiramente o núcleo é identificado, depois, à esquerda do núcleo, o ataque é projetado maximamente, respeitando a sonoridade decrescente nas bordas.

(5)

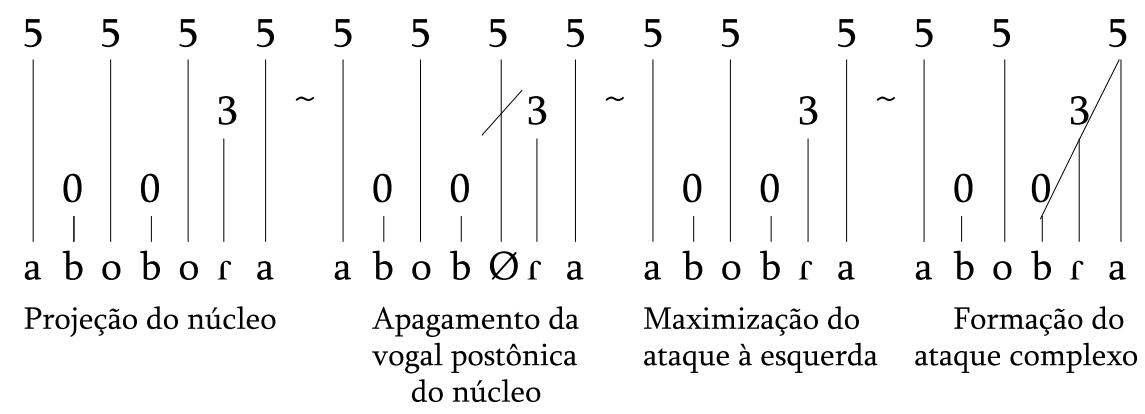


O apagamento da vogal postônica, em palavras como "físico", "príncipe", “cócegas", faz com que o segmento fora da sílaba seja incorporado à sílaba tônica e passe a ocupar, então, a posição de coda. Esse fato se justifica por a condição de língua particular permitir a obstruinte /s/ em posição de coda e, certamente, por o PSS exigir que a sonoridade seja crescente em direção ao núcleo e decrescente em direção à coda. Assim, o /s/ não poderia formar um ataque complexo $\mathrm{com} / \mathrm{k} /$, visto que, pela escala de sonoridade, o /s/ apresenta grau de sonoridade 1 , enquanto que o $/ \mathrm{k} /$ apresenta grau 0 .

(6)

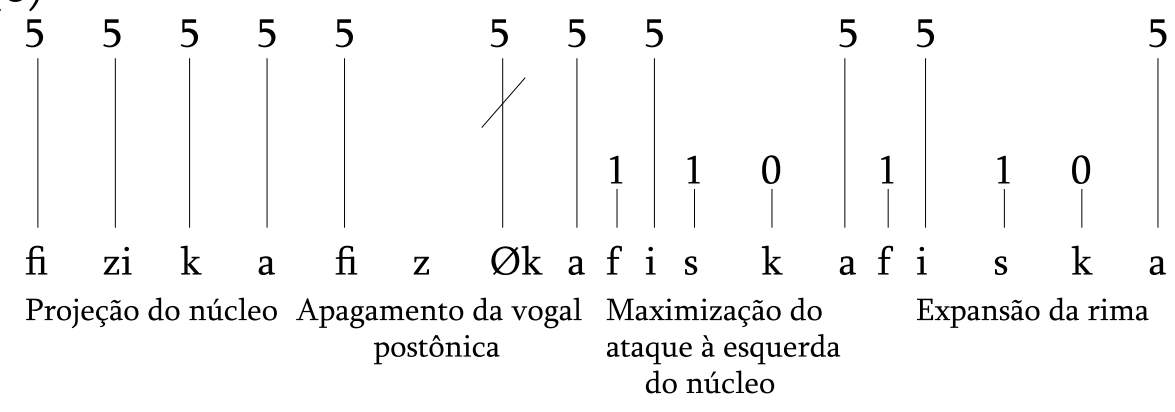

Collischonn (2006, p. 44) considera que "o apagamento da vogal implica reformulação da estrutura silábica”. A autora apresenta como exemplos as palavras: ácido > a[s]do e xícara> xícra, que ao perderem o núcleo da sílaba postônica, perdem também o nó silábico e, consequentemente, a consoante anterior à vogal apagada fica flutuando. Com a reformulação da sílaba, as palavras que antes apresentavam três sílabas passam a ter apenas duas e, ainda, a consoante dissociada do nó silábico muda de posição, podendo associar-se ao ataque ou, então, à coda de uma das sílabas restantes.

(7)

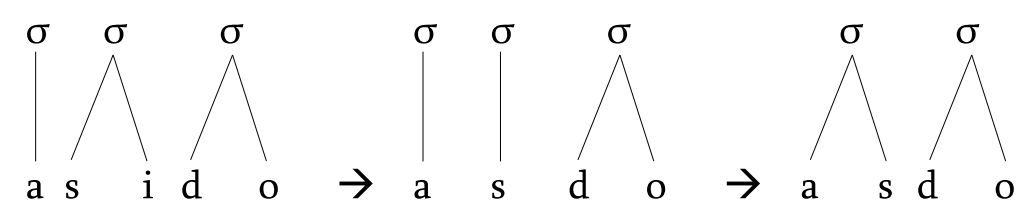

(COLLISCHONN 2006, p. 44) 
Nossos dados demonstraram que a ressilabação está presente como consequência da síncope, mas não apenas como apresentado por Collischonn (2006). Na verdade, os dados coletados comprovam que a natureza dos segmentos adjacentes pode sofrer modificações (8) ou ainda a estrutura da margem se reconfigurar (9).

(8) cócegas > cósca

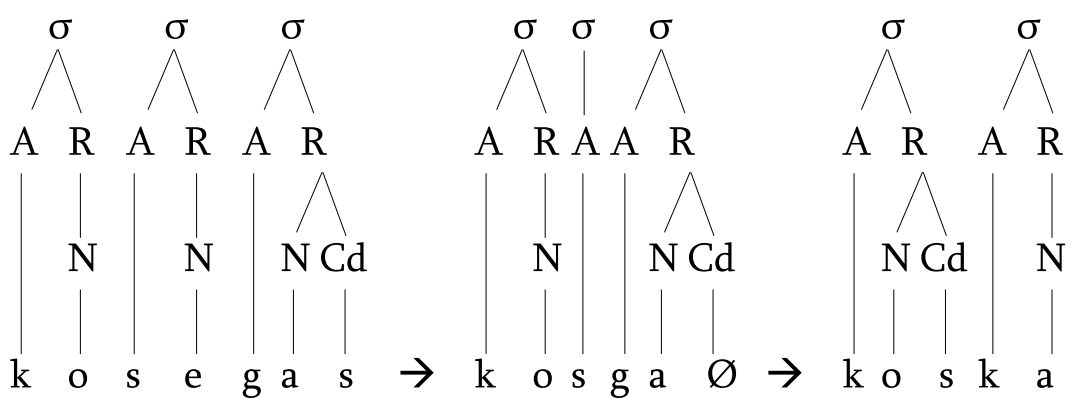

Podemos observar que em (8) o apagamento da vogal postônica cria uma nova estrutura silábica. Pela ressilabação, o /s/ é incorporado à rima da antepenúltima sílaba, formando uma rima ramificada, ou seja, o segmento passa a ocupar a coda da sílaba tônica. Todavia, o segmento adjacente também sofre os efeitos da síncope. Neste caso, o segmento /g/ perde a sonoridade, passando a /k/. Isso significa que a ressilabação provoca um outro processo fonológico, a saber, a assimilação, conforme veremos mais adiante.

A ressilabação opera para que as sílabas estejam de acordo com a fonotática da língua. Entretanto, em algumas palavras, o apagamento da vogal postônica deixa um segmento flutuante que não pode ser incorporado em nenhuma das sílabas adjacentes. Dessa forma, a estrutura da margem se reconfigura, isto é, outro segmento é apagado para que a ressilabação aconteça respeitando o padrão silábico do $\mathrm{PB}$. 
(9) Relâmpago> relâmpu

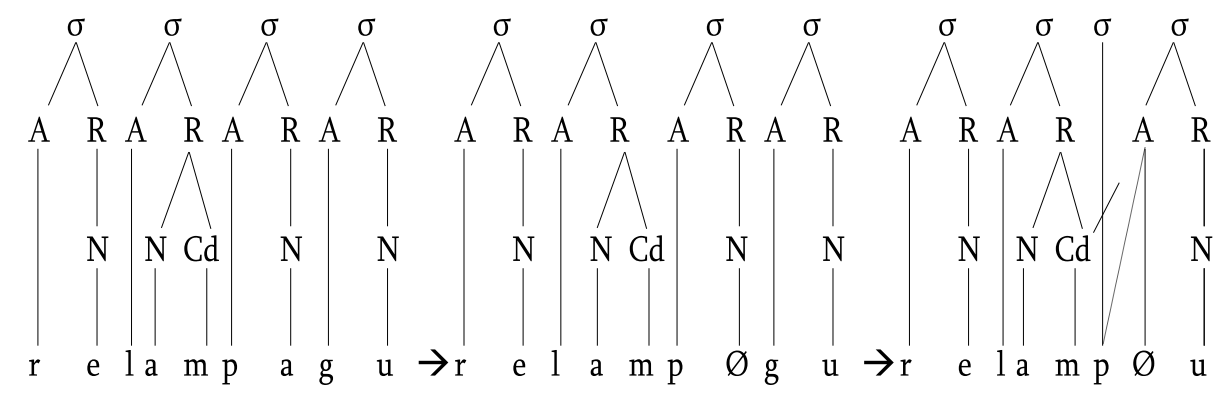

Em (9), com o apagamento da vogal postônica, a palavra "relâmpago" não poderá ser ressilabada como "re.lamp.go", tampouco como "re.lam.pgo". Para resolver esse problema, mais um segmento é apagado na margem da sílaba. O mesmo acontece em outras palavras proparoxítonas, conforme parte de nosso corpus do Sudoeste Goiano.

(9)

bêbado > bêbu
lâmpada $>$ lâmpa
úlcera $>$ urça
frigorífico > frigorífu
relâmpago > relâmpu

Enfim, a ressilabação é guiada por princípios universais, como o Princípio de Sonoridade Sequencial, o Princípio de Licenciamento Prosódico e o Princípio de Maximização do Ataque e, também, pela condição delíngua particular. Nas línguas naturais, a estrutura silábica ótima é formada por CV. A síncope, por sua vez, desestrutura o padrão canônico $\mathrm{CV}$, pois transforma estruturas simples, formadas por $\mathrm{CV}$, em estruturas complexas formadas por CVC (vi.gé.si.mo > vi.gés.mo) ou CCV (pé.ta.la > pe. tla). É nesse ponto que questionamos Amaral (1999). A autora assevera que no Português Moderno as palavras proparoxítonas são, na maioria, vocábulos cultos, eruditos e que mesmo palavras comuns como "sábado", "estômago" tendem a ser transformadas em paroxítonas pela Lei do 
Menor Esforço ou pelo princípio de economia ou por tendência em seguir o padrão da língua. Contudo, apesar de a palavra diminuir e cair no padrão default do acento, estruturas silábicas complexas se formam.

\subsection{Assimilação}

Um dos processos fonológicos mais comuns nas línguas do mundo é a assimilação. Por esse processo, um segmento assume traço(s) de um segmento vizinho, isto é, uma consoante pode assimilar traços de outra consoante ou traços de uma vogal, assim como uma vogal pode assimilar traços de outra vogal ou de uma consoante.

De acordo com Clements and Hume (2001, p. 258), as regras de assimilação são assim caracterizadas: uma característica de um segmento A propaga-se para um segmento vizinho $B$. Sendo assim, o segmento vizinho $\mathrm{B}$, ao assimilar uma característica de $\mathrm{A}$, é modificado, conforme ilustrado em (10):

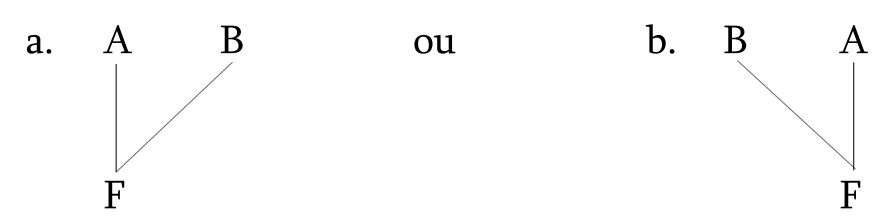

Isso significa que, entre dois segmentos vizinhos, um influencia de alguma forma o outro. Como representado em (10) acima, a assimilação pode ser progressiva (10a) ou regressiva (10b). No primeiro tipo de assimilação, o som altera por influencia do segmento precedente, já no segundo tipo, assimilação regressiva, o som sofre alteração por influência do segmento seguinte.

$\mathrm{Na}$ literatura, o tipo de assimilação mais comum nas línguas do mundo é a regressiva. No entanto, os dados por nós coletados e analisados demonstraram que a síncope nas proparoxítonas do $\mathrm{PB}$ - aqui representadas pela variante do Sudoeste Goiano - provoca, naturalmente, 
tanto a assimilação regressiva quanto a progressiva, conforme destacamos pelos exemplos em (11):

(11) Assimilação progressiva

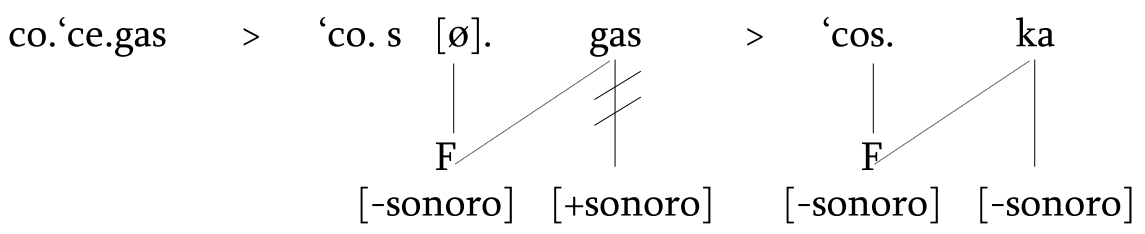

No exemplo apresentado em (11), a consoante /g/, que tem o traço [+sonoro], assimila o traço [-sonoro] de /s/, passando a /k/. Esse fato se justifica pela realização de $/ \mathrm{S} /{ }^{2}$ em final de sílaba mediais.

O mesmo acontece com a palavra "pêssego" que, após sofrer a síncope, e já no processo de ressilabação, sofre também a assimilação. Nessa palavra, nossos dados revelaram os dois tipos de assimilação: progressiva e regressiva. Para exemplificar, em (12), a palavra "pêssego" foi pronunciada por um determinado informante como "pescu", isso significa que a característica [-sonora] de /s/ propagou-se para /g/, modificando, assim, o segmento por meio da assimilação progressiva. No entanto, a mesma palavra foi pronunciada por outro informante como "pezgu", conforme representação em (12). Assim, contrariando a assimilação progressiva, o segmento /g/ espraia o traço [+sonoro] para o /s/ que, assim, passa a /z/. Neste caso, a assimilação é regressiva.

(11) Assimilação progressiva 'pes.se.go > 'pe.s [ø]. go
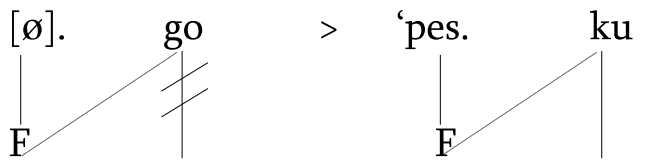

$$
\text { [-sonoro }] \text { [+sonoro }] \text { [-sonoro }] \text { [-sonoro }]
$$

(12) Assimilação regressiva

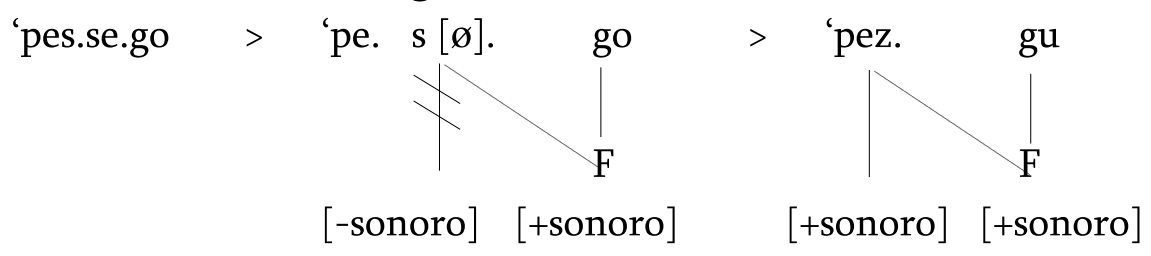


Semelhantemente, a palavra "analgésico" ora apresentou assimilação progressiva, ora regressiva. Por essa razão, a pronúncia da palavra ressilabada ocorreu como "analgéscu" ou como "analgésgu". No primeiro caso, assimilação regressiva, o segmento /z/ assimilou o traço [-sonoro] de /k/, ou seja, o / $\mathrm{z} /$ copiou a sonoridade da consoante seguinte e passou a /s/. Já no segundo, assimilação progressiva, o segmento $/ \mathrm{k} /$ assimilou a sonoridade de /z/, passando, então, a /g/.

(13) Assimilação progressiva

a. nal.'ge. si. co > a. nal.'ge. $\mathrm{z}$ [ø]. $\mathrm{ku}>$ a. nal.'gez. gu

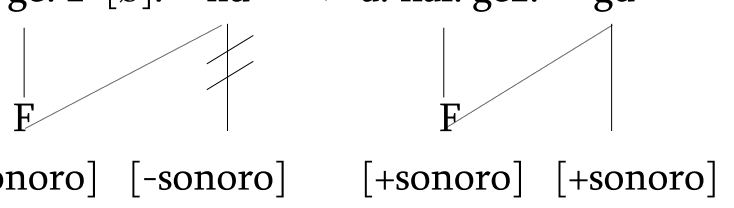

(14) Assimilação regressiva

a. nal.'ge. si. co > a. nal.'ge. $z$ [ø]. $\mathrm{ku}>$ a. nal.'ges. $\mathrm{ku}$

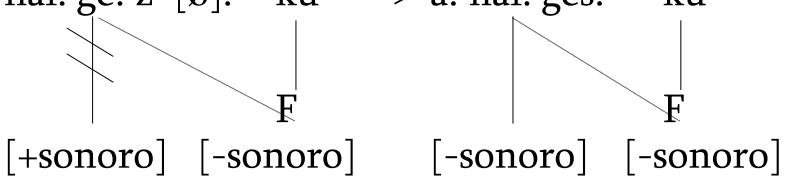

A assimilação regressiva está presente em outras palavras como:

(15)

vigésimo $>$ vigésmu
dízimo $>$ dísmu
físico $>$ fisku

Em todos os casos, a consoante da última sílaba espraia o traço [-sonoro] para o segmento /z/. Por essa razão, o segmento perde a sonoridade, e o falante o pronuncia como /s/.

Para sumarizar, o processo de assimilação, em nossos dados, ocorreu em palavras que apresentavam na segunda sílaba o segmento fricativo /s/ e /z/ na posição de ataque. Com o apagamento da vogal postônica, a consoante, representada pelo arquifonema /S/, fica 
subespecificada nos casos de assimilação regressiva. Assim, no processo de ressilabação, essa consoante passa a ocupar a coda da sílaba tônica, recebendo um traço especificador da consoante seguinte. Já nos casos de assimilação progressiva, a consoante /S/ realiza-se como /s/. Assim sendo, o traço [-sonoro] prevalece, e consequentemente, a consoante seguinte assimila a sonoridade desse segmento. Em (16) e (17), apresentamos um resumo dos dois tipos de assimilação encontrados no corpus da pesquisa.

(16) Assimilação progressiva

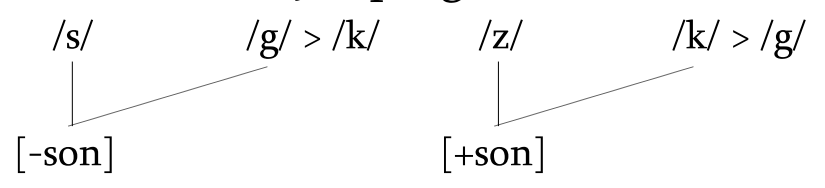

(17) Assimilação regressiva

$\underset{[+ \text { son }]}{/ \mathrm{S} />/ \mathrm{z} /} / \mathrm{S} />/ \mathrm{s} /\left.\right|_{[- \text {son }]} ^{/ \mathrm{k} /} \quad / \mathrm{S} />/ \mathrm{s} /\left.\right|_{[- \text {son }]} ^{/ \mathrm{m} /}$

\subsection{Reestruturação dos pés}

A síncope desencadeia um processo que transforma palavras com padrão de acento marcado, isto é, com acento antepenúltimo, em um padrão não-marcado ${ }^{3}$. Contudo, algumas palavras ${ }^{4}$ como "último", "fábrica", "lírica", "epilético" não suportam tal processo, mostrando-se resistentes. Esse fato se justifica pelo processo de ressilabação, já que a supressão da vogal só acontece se houver contexto favorável para reestruturação das sílabas. Assim, em decorrência dos processos aqui apresentados, outro fenômeno torna-se inevitável: a reestruturação dos pés.

Lembremos que, no modelo de Hayes (1995), os pés são sempre binários, podendo ser dissilábicos $(\sigma \sigma)$ ou bimoráicos $(\mu \mu)$, ou ilimitados 5 . Baseando-se neste modelo, Bisol (2002) define as regras de acento do Português do Brasil da seguinte forma:
3 As paroxítonas apresentam o padrão default do acento no $\mathrm{PB}$, por esse motivo são consideradas nãomarcadas.

${ }^{4}$ Dados da autora.

${ }^{5}$ Ver seção 2.1. 
Domínio: Palavra lexical. Aplicação cíclica em não-verbos; não cíclica, em verbos.

Extrametricidade: Atribua extrametricidade a formas nominais lexicalmente marcadas; e a verbos aplique a regra seguinte: Marque como extramétrica a sílaba final da primeira e da segunda pessoa do plural de tempos de imperfeito; nos demais casos, a coda com status de flexão.

Regra geral: Forme um troqueu mórico se a palavra acabar em sílaba ramificada; nos demais casos, um troqueu silábico, não-iterativamente, da direita para a esquerda.

Regra Final: promova o cabeça do pé a acento primário. (BISOL, 2002, p.107-108).

O mecanismo da extrametricidade élexicalmente atribuído, conforme Bisol, a formas nominais marcadas. Sob essa ótica, as palavras com acento antepenúltimo são lexicalmente marcadas, ou seja, são formas menos recorrentes no $\mathrm{PB}$. E, por esse motivo, a sílaba final não acentuada da palavra prosódica é marcada extramétrica, ficando, pois, invisível às regras de acento. Com o pé binário já formado, a sílaba é recuperada por uma regra de Adjunção da Sílaba Extramétrica (ASE).

Pela regra geral, o troqueu mórico é formado quando a palavra terminar em sílaba pesada, isto é, com rima ramificada. Caso contrário, o troqueu silábico é formado, seguindo dois parâmetros, a saber: a escansão do pé é não-iterativa e da direita para esquerda. Após aplicação desta regra, aplica-se a regra de fim, a qual determina que seja atribuído, ao cabeça do pé, acento primário, conforme representação em (18). 


$\begin{array}{llll} & (\mathrm{x} & \cdot) & \\ \text { Troqueu silábico: } & \sigma & \sigma & <\sigma> \\ & & & \\ & \text { má. gi. } & \text { co } \\ \text { Extrametricidade } & \text { má. gi. } & <\mathrm{co}> \\ \text { Regra geral } & \left(\begin{array}{lll}\sigma & \sigma\end{array}\right) & \\ & (\mathrm{x} & \cdot) & \\ \text { Regra final } & (\mathrm{x} & & )\end{array}$

Forma lexicalmente não-marcada

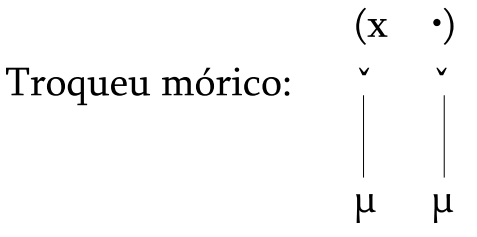

ven.ti.la. dor

Extrametricidade ven.ti.la. dor

Regra geral

Regra final
6 Amaral (2002, p.

103) considera que "o tipo de pé mais comum é o dissilábico, e se caracteriza por uma sílaba forte e uma sílaba fraca. A sílaba forte, a mais proeminente, é chamada de cabeça do pé. Sendo a proeminência à esquerda, o pé é um troqueu que, se contar sílabas é silábico, e se contar moras, é mórico. Se a proeminência for à direita, o pé é um iambo". antepenúltimo podem ser escandi
troqueu silábico e troqueu mórico.

Assim, exemplificamos, em (19), as proparoxítonas "chácara" e "fósforo". Essas palavras têm a última sílaba extramétrica, com um troqueu silábico não-iterativo da direita para esquerda. A aplicação da regra final somente acontece após a incorporação da sílaba extramétrica ao pé. 
a. Troqueu silábico

\begin{tabular}{|c|c|c|}
\hline Léxico & chácara & fósforo \\
\hline Silabação & cha ca ra & fos fo ro \\
\hline Extrametricidade & $<$ ra $>$ & $<$ ro $>$ \\
\hline Troqueu silábico & $\left(\begin{array}{ll}\mathrm{x} & \bullet\end{array}\right)$ & $\left(\begin{array}{ll}\mathrm{x} & \cdot\end{array}\right)$ \\
\hline ASE & $(\mathrm{x} \cdot \bullet)$ & $(\mathrm{x} \cdot \bullet)$ \\
\hline Regra final & $(\mathrm{x} \quad)$ & $(\mathrm{x} \quad)$ \\
\hline Saída & [ akra $]$ & [fosfru] \\
\hline
\end{tabular}

Uma análise mórica, conforme (19), deixaria uma sílaba em palavras como fósforo, fora do pé. Para Hayes, se essa sílaba fosse escandida em um único pé, ter-seia um pé degenerado, isto é, um pé mal-formado. É por essa razão que o autor deixa a sílaba fora do pé, sem ser escandida. O problema é que teríamos, assim, duas sílabas não escandidas: a sílaba extramétrica e a penúltima. Para resolver esse problema, utilizamos a regra de Adjunção da Sílaba Extramétrica (ASE), proposta por Bisol (2002), fazendo com que as duas sílabas sejam associadas ao pé, antes da aplicação da regra final. Tomemos como exemplo a representação abaixo.

a. Troqueu mórico

\begin{tabular}{|c|c|c|c|c|}
\hline Léxico & chácara & & fósforo & \\
\hline Silabação & cha ca & ra & fos fo & ro \\
\hline Extrametricidade & $\mu$ & $<\mathrm{ra}>$ & $\mu \mu \quad \mu$ & $<$ ro $>$ \\
\hline Troqueu mórico & $\left(\begin{array}{ll}\mathrm{x} & \cdot\end{array}\right)$ & & $(\mathrm{x} \cdot)^{\bullet}$ & \\
\hline ASE & $(\mathrm{x} \cdot$ & $\cdot)$ & $(\mathrm{x} \cdot$ & $\cdot)$ \\
\hline Regra final & $(\mathrm{x}$ & ) & $(\mathrm{x}$ & \\
\hline Saída & [ Jakra] & & {$[$ fosfru $]$} & \\
\hline
\end{tabular}

As palavras, ora apresentadas, ao sofrerem os efeitos da síncope, fazem com que o pé se reestruture. Isso porque o apagamento da vogal acontece no membro fraco do pé, ou seja, na penúltima sílaba. A sílaba extramétrica, que na silabação é adjungida na estrutura do constituinte antes da regra final, agora, é incorporada ao pé, na reestruturação. A incorporação, neste caso, é necessária 
para formar um constituinte binário. No entanto, mais do que a incorporação da sílaba, antes extramétrica, nossos dados têm demonstrado que o pé passa por uma completa reestruturação, haja vista a perda e, ao mesmo tempo, acréscimo de segmentos. Formalizamos abaixo a reestruturação dos pés nos troqueus silábico e mórico.

Troqueu silábico

Léxico

Silabação

Extrametricidade

Troqueu silábico

Síncope

Reestruturação do pé

Regra final

Saída

(22)

Troqueu mórico

Léxico

Silabação

Extrametricidade

Troqueu mórico

Síncope

Reestruturação do pé

Regra final

Saída

\begin{tabular}{|c|c|c|c|}
\hline chácara & & fósforo & \\
\hline cha ca & ra & fos fo & ro \\
\hline & $<\mathrm{ra}>$ & & $<\mathrm{ro}>$ \\
\hline $\mathrm{x} \quad \cdot)$ & & $\left(\begin{array}{ll}(x & \cdot\end{array}\right)$ & \\
\hline$\varnothing)$ & $<\mathrm{ra}>$ & $\left(\begin{array}{ll}\mathrm{x} & \varnothing\end{array}\right)$ & $<\mathrm{ro}$ \\
\hline$\left(\begin{array}{ll}\mathrm{x} & \cdot\end{array}\right)$ & & $\left(\begin{array}{ll}(\mathrm{x} & \cdot\end{array}\right)$ & \\
\hline$\left(\begin{array}{ll}\mathrm{x} & )\end{array}\right.$ & & $\left(\begin{array}{ll}\mathrm{x} & )\end{array}\right)$ & \\
\hline fakra] & & [fosfru] & \\
\hline
\end{tabular}

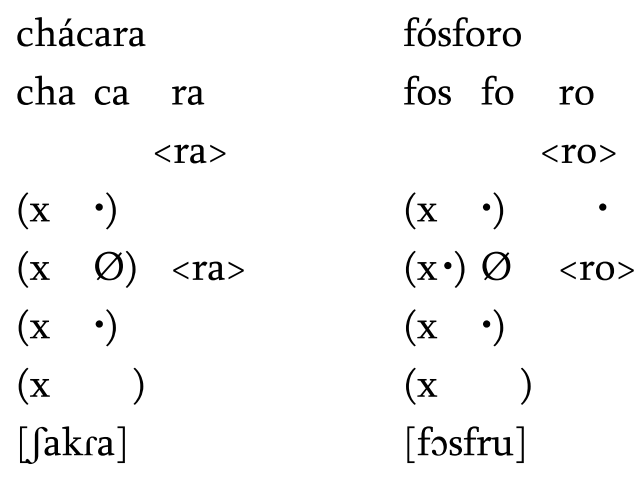

No troqueu silábico (21), o apagamento da vogal postônica acontece, nos dois casos, dentro do pé. Cabe, contudo, ressaltar que, para esse tipo de pé, o peso silábico é irrelevante, ou seja, apenas sílabas são consideradas, independentemente de serem pesadas ou leves. Já no troqueu mórico, em palavras com a sílaba tônica pesada 'fós.fo.ro', a síncope ocorre fora do pé. Nessas palavras, a incorporação ${ }^{7}$ da sílaba extramétrica cria um troqueu com três moras, isto é, um troqueu irregular ${ }^{8}$, como em (23).
7 Bisol (2002, p. 107) considera que a incorporação só é admitida quando obedecer à restrição básica de estrutura do pé e que a escansão exaustiva não é uma exigência do modelo de Hayes.

${ }^{8} \mathrm{O}$ troqueu irregular apresenta semelhanças com o troqueu mórico, pois se mostra sensível ao peso silábico. Hayes (1995, p. 76) pontua que o troqueu irregular pode ser composto por uma sílaba pesada, seguida de uma leve, com proeminência à esquerda.

$\begin{array}{lll}\left(^{*}\right. & .) & \left(^{*}\right) \\ \sigma & \vee & \sigma \\ \mu & \mu \mu & \mu \mu\end{array}$




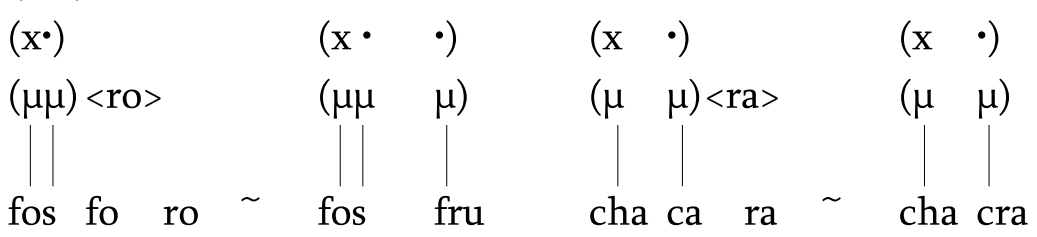

Segundo Hayes (1995), o pé canônico é formado por duas sílabas ou por duas moras. Portanto, se adotássemos moras em nossa análise, estaríamos, também, admitindo o troqueu irregular. Assim, ora o apagamento da vogal aconteceria dentro do pé, formando um troqueu mórico, ora fora do pé, formando um troqueu irregular. Diante disso, consideramos que o troqueu mórico não é a melhor alternativa para explicar a síncope nas proparoxítonas, haja vista a inconstância na estruturação dos constituintes pós-apagamento.

Sendo assim, a reestruturação do pé culmina na construção de troqueus silábicos, pois esse tipo de pé dá conta da nova configuração métrica da palavra após a síncope não apenas nos vocábulos que apresentam rima ramificada na sílaba tônica, mas também naqueles que apresentam apenas sílabas leves em todas as posições. A incorporação da sílaba extramétrica, outro fator favorecedor para essa tipologia de pé em nossa pesquisa, cria sempre um pé dissilábico com proeminência à esquerda. Com essa reestruturação do pé, o acento, que antes prevalecia na antepenúltima sílaba, passa para a penúltima, fazendo com que as palavras proparoxítonas se estabeleçam como paroxítonas.

\section{Considerações finais}

O objetivo principal deste artigo foi analisar o efeito da síncope em palavras proparoxítonas no Sudoeste Goiano. Esse processo fonológico, que teve suas origens no Latim Vulgar, continua vivo no PB, transformando palavras proparoxítonas em paroxítonas no Sudoeste de Goiás. Contudo, a síncope não provoca 
apenas a mudança na posição do acento, mas também desencadeia outros processos fonológicos. Assim sendo, esse estudo, com base nos pressupostos da Fonologia Métrica, acompanhado de análises variacionistas, permitiu chegar às seguintes conclusões:

1) Nem todas as palavras proparoxítonas sofrem o apagamento da vogal postônica. No $\mathrm{PB}$, os segmentos licenciados para posição de ataque ou de coda devem respeitar o Princípio de Sonoridade Sequencial e as condições de língua particular. Dessa forma, palavras como "dúv[i]da, "epilét[i] co", “ép[o]ca” não poderiam formar ataques complexos (vd, tk, pk), tampouco codas com as oclusivas /v,t,p/ fechando sílaba, pois estariam ferindo os dois princípios.

2) Os segmentos que compõem a sílaba postônica e os segmentos da sílaba átona final podem favorecer a síncope, ou seja, se a sílaba átona final tiver uma líquida lateral ou vibrante e a postônica uma oclusiva, ataques complexos bem formados são estruturados (másc[u]lo > másclu; pét[a]la > pétla; xíc[a]ra > xícra). Caso a sílaba postônica tenha um segmento soante $/ \mathrm{S}, \mathrm{N}, \mathrm{r} /$ na posição de ataque, como em "co[r]ego", "có[s]egas", "ô[n]ibus", a vogal tende a ser apagada, fazendo com que o segmento soante seja incorporado à coda da sílaba tônica.

3) No processo de ressilabação, o segmento que antes ocupava a posição de ataque será incorporado à sílaba tônica ou à sílaba átona final. A incorporação desse segmento deve seguir o Princípio de Sonoridade Sequencial e o Princípio de Maximização do Ataque.

4) Com a ressilabação, a natureza dos segmentos adjacentes pode modificar, isto é, um segmento assume traço(s) de um segmento vizinho. Em nossos dados, verificamos a ocorrência de dois tipos de assimilação: progressiva e regressiva. 
5) No processo de reestruturação dos pés, constatamos que o troqueu silábico é o tipo de pé que mais se ajusta à síncope nas proparoxítonas. Com essa reestruturação, o acento, que antes incidia na antepenúltima sílaba, passa para a penúltima, evidenciando a mudança do acento para o padrão default do PB. 


\section{Referências}

AMARAL, M. P. As proparoxítonas: teoria e variação. Tese de Doutorado. Porto Alegre: PUCRS, 1999.

AMARAL, M. P. A síncope em proparoxítonas. IN: BISOL, Leda; BRESCANCINI, Cláudia (org). Fonologia e Variação: Recortes do Português Brasileiro. Porto Alegre: EDIPUCRS, 2002. 99-126.

BATTISTI, E.; VIEIRA, M.J.B. O sistema vocálico do português. IN: BISOL, Leda (org.). Introdução a estudos de fonologia do português brasileiro. Porto Alegre: EDIPUCRS, 2005. 171-205.

BISOL, L. O sândi e a ressilabação. Letras de Hoje, Porto Alegre, v.31, n.2, p.159-168, jun.1996.

BISOL, L. O acento, mais uma vez. Letras \& Letras, Uberlândia, 18 (2) 103-110, jul./dez. 2002.

BISOL, L. A neutralização das átonas. Revista Letras, Curitiba, n.61, especial, Editora UFPR, p. 273-283, 2003.

BONET, E; MASCARÓ, J. On representation of contrasting rhotics. In: MARTÍNEZ-GIL, F; MORALES-FRONT, A (ed.) Issues in the Phonology and Morphology of the Major Iberian Languages. Washington: Georgetown University Press, 1997.

CALLOU, D; LEITE, I. Iniciação à fonética e à fonologia. 9 ed. Rio de Janeiro: Jorge Zahar Ed., 2003.

CÂMARA JR, J. M. Problemas de Linguística Descritiva. 8 ed. Petrópolis: Vozes, 1976.

CLEMENTS, G. N.; HUME, E. V. The Internal Organization of Speech Sounds. In: GOLDSMITH, J. (org). The Handbook of Phonological Theory. London: Blackwell, 2001.

COLLISCHONN, G. Fonologia do português brasileiro, da sílaba à frase. Porto Alegre: Gráfica UFRGS, 2006. 
HAYES, B. Metrical Stress Theory: Principles and Case Studies. Chicago: University of Chicago Press, 1995.

SELKIRK, E. The syllable. IN: HULST, H; SMITH, N. The Structure of Phonological Representations. Foris Publication, 1982. 